\title{
Pingefias
}

\section{Reflexiones sobre la escritura en ciencias Desde la experiencia de la serie Pre Impresos Estudiantes, Facultad de Ciencia y Tecnología}

\author{
Juan Carlos Bustos* / juancarlosbustos@yahoo.com
}

La serie Pre Impresos se ha planteado como un espacio para publicar los trabajos de los estudiantes de la Facultad de Ciencia y Tecnología, consolidándose como una oportunidad de diálogo y circulación del conocimiento, sin distingo de temas o enfoques. En esta convocatoria permanente el énfasis está puesto en el acompañamiento a los autores para el desarrollo de habilidades escriturales, procurando que alcancen los más altos niveles de calidad académica en su trabajo. Se espera con esto darle mayor visibilidad a la actividad de los maestros de ciencias en formación y el debido reconocimiento de la dimensión social de la ciencia y su enseñanza. A continuación se presentan algunas consideraciones y reflexiones al respecto.

\section{El deseo de comunicar}

Con esta serie se quiere destacar el carácter social y comunicativo de la escritura, enfatizando su contribución en la socialización de las ideas, pues sólo se conoce aquello que se dice. Ya que la palabra escrita contribuye de manera decisiva a hacer visible el trabajo de los autores, así como a la conformación de comunidades académicas ampliadas, tanto dentro, como fuera de la Universidad.

Del mismo modo, el desarrollo de la habilidad lingüística se da a través del intercambio, esto es, de forma comunicativa; como en el caso de la relación entre maestros y estudiantes. Además, el conocimiento es una construcción discursiva, por ello, lenguaje y escritura son y serán fundamentales en la educación, ya que constituyen la materia prima para la construcción del pensamiento. Así, la comunicación construye relaciones de fuerza e identificación entre las personas y sirve para definir el lugar de cada individuo en un grupo. Pues cuando intercambiamos información no sólo la difundimos, sino que construimos representaciones de nosotros mismos, de los otros y de las cosas de las que "hablamos", es decir, damos forma al mundo.

En este contexto, los autores de los diferentes títulos publicados en los
Pre Impresos asumen el reto de la comunicación. En la voluntad expresa de comunicar, ponen de manifiesto el reconocimiento del otro. No solo privilegiamos la expresión, en el sentido de dar a conocer, pues no sólo se escribe para publicar, sino que fundamentalmente nos interesa la interlocución con los otros y su reconocimiento: esa es la idea central que orienta y da sentido a nuestra actividad en este proyecto.

\section{La escritura}

Nuestra estrategia metodológica consiste en centrar la atención en los procesos escriturales y no en los escritos, toda vez que los textos constituyen un pretexto para ampliar la comprensión, desarrollar capacidad crítica y, esencialmente, para aprender ciencias en forma comprensiva. A este respecto, consideramos que la escritura, al implicar una distancia espacial y temporal entre el autor del texto y sus posibles lectores, obliga a hacer explícitas las claves necesarias para interpretarlo de acuerdo a la intención de quien lo escribe, dado que el escrito, una vez publicado, se

\footnotetext{
* Docente de la Universidad Pedagógica Nacional. Maestría en Comunicación, Universidad Iberoamericana, México.
} 


\section{Girefit:}
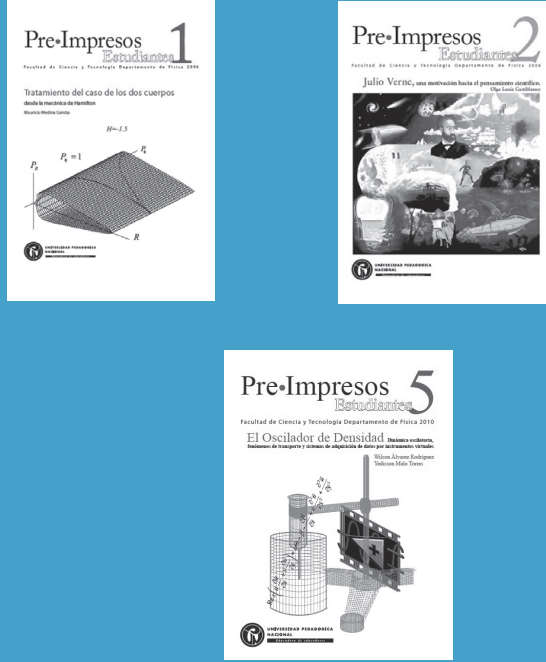

vuelve autónomo, se independiza de su autor. De otra parte, concebimos la escritura en dos sentidos: primero, la escritura es un oficio y, como tal, requiere de disciplina, pues se aprende y se perfecciona con la práctica constante; segundo, la escritura es una actividad intelectual, por cuanto supone el desarrollo de la capacidad discursiva, dado que ayuda a aclarar y a concretar nuestras ideas, a tomar distancia de ellas.

\section{La narración de la ciencia}

Como la escritura es un aspecto fundamental de nuestra propuesta, es preciso destacar la importancia de su cualificación, por ello también le apostamos al recurso de la narración para aprender a escribir, pulir el discurso y desarrollar la capacidad discursiva.

Los relatos resultan útiles para propiciar la comprensión. Para comenzar, todas las narraciones contienen información completa; así, la escritura sobre temas científicos debe garantizar que la información sea suficiente y necesaria para precisar el ámbito de interpretaciones del texto de forma adecuada, pues si falta información no se comprende.
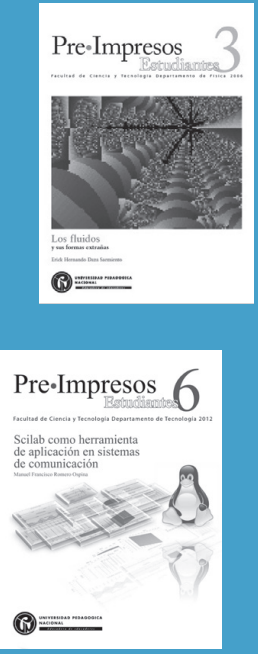

Otro punto importante es el tratamiento de la información, es decir, la manera como se aborda el tema. Los relatos gozan del atributo de lo ameno, lo que no debería ser monopolio de la literatura. Se espera que, en lo posible, los textos sobre temas de la ciencia y su enseñanza también cautiven al lector y esto exige un uso más refinado y sutil del lenguaje, para que los documentos tengan la fluidez necesaria y se dejen leer con facilidad.

Por último, los relatos son coherentes, es decir que tienen sentido, dado que comprenden narración y experiencia. Hablamos de lo que sabemos, de lo que nos interesa, de nuestras experiencias cotidianas 0 , como en el caso de los documentos de la serie Pre Impresos, de una experiencia de conocimiento.

Adicionalmente, la cualificación de la escritura pasa por el reconocimiento de los modelos que usamos para escribir. Los modelos de escritura que nos inspiran pueden ser los libros de literatura, los textos periodísticos, entre otros. Lo cierto es que aportan y enriquecen nuestros referentes escriturales, nos muestran

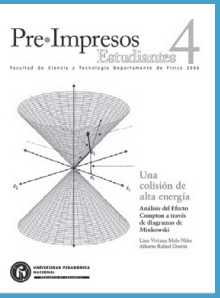

cómo abordar nuestro propio proceso de escritura. Consideramos que al cualificar el proceso también se cualifica el producto; en este sentido, es importante enriquecer nuestra experiencia, pues el énfasis de esta publicación está en la formación escritural de los futuros maestros e investigadores.

\section{Ciencia, lenguaje y escritura}

Cualquier idea o concepto que se nos ocurra puede existir porque existen las palabras que lo representan. Recordemos que la ciencia es actividad social y que la comunicación no es algo accesorio en los procesos de cognición, sino un aspecto fundamental. En consecuencia, es conveniente resaltar la base sobre la que se funda esa relación social, que es el intercambio de palabras.

La ciencia también pasa por el lenguaje, pues la comunicación de la ciencia se realiza en la lengua natural, por eso se concluye que no hay comprensión sin entendimiento, ni ciencias sin lenguas, tal como lo afirma Levy Leblond.

Así pues, con este proyecto reafirmamos la convicción de que la escritura y la investigación son aspectos constitutivos de la vida académica y que resultan particularmente relevantes para los maestros en formación, por cuanto fomentan la interlocución y promueven el debate de razones, constituyéndose en actividades esenciales del trabajo académico para pensar y asumir posición frente a nuestra labor profesional. 